\title{
DETEKSI RABUN JAUH (MIOPIA)BERBASIS PENGOLAHAN CITRA DIGITAL MENGGUNAKAN METODE BWAREA
}

\author{
C. Anwar ${ }^{1}$, D. Lusiyanti2 ${ }^{2}$ dan I W. Sudarsana ${ }^{3}$ \\ 1,2,3 Program Studi Matematika Jurusan Matematika FMIPA Universitas Tadulako \\ Jalan Sukarno-Hatta Km. 9 Palu 94118, Indonesia \\ 1anwar.chairil07@gmail.com, 2desylusiyanti@gmail.com, 33sudarsanaiwayan@yahoo.co.id
}

\begin{abstract}
Myopia is a condition in which a person can see an object at close range in well but hard to seeing distant object in far. One of method for the detection myopia processing digital based image is Bwarea method. Bwarea technique image is processing on the number of pixels in the contained in a picture. This study attempts to get an Bwarea of the eye in that Myopia or not. In this study sample takes from students of Mathematics Study Program FMIPA UNTAD in stage 2009 to 2016 that divided in two categories namely students with Myopia or not. We have the research the value Bwarea for students of Mathematics with Myopia condition is more that 37580,9 , otherwise $[0,31659]$ states that the students are not Myopia. We can not classify the students condition (Myopia or not) where the value of Bwarea lies on interval $(31659,37580.9)$. By using kolmogorov-smirnovtest, we have that the sample used in this research is normal and so the sample is a representation of the population.
\end{abstract}

Keywords : Bwarea, Digital Image Processing, Myopia

\section{ABSTRAK}

Miopia merupakan suatu kondisi dimana seseorang dapat melihat objek pada jarak dekat dengan baik tetapi mengalami gangguan ketika melihat objek yang jauh. Salah satu metode pendeteksian Miopia berbasis pengolahan citra digital adalah metode Bwarea. Bwarea merupakan teknik pengolahan citra yang memperkirakan jumlah piksel dalam daerah yang terkandung pada sebuah gambar. Penelitian ini bertujuan untuk mendapatkan nilai Bwarea dari Miopia dan tidak Miopia. Pada penelitian ini sampel yang digunakan ialah mahasiswa Matematika FMIPA UNTAD tahun 2009-2016 yang dibagi dua kategori yaitu mahasiswa Miopia dan tidak Miopia. Nilai Bwarea mata mahasiswa Matematika yang Miopia adalah $\geq 37580,9$, untuk mata tidak Miopia dengan interval $[0,31659]$ dan untuk nilai Bwarea dengan interval $(31659,37580.9)$ tidak terdeteksi. Hasil uji menggunakan kolmogorov-smirnov menunjukkan sampel berdistribusi normal, sehingga sampel dapat mewakili populasi.

Kata kunci : Bwarea, Pengolahan Citra Digital, Miopia 


\section{PENDAHULUAN}

\subsection{Latar Belakang}

Mata berfungsi untuk melihat dan menafsirkan bentuk, warna, serta dimensi bendabenda di dunia dengan mengolah cahaya yang direfleksikan oleh benda yang melepaskan cahaya (Rochmad, 2011). Gangguan penglihatan atau penyakit mata seringkali terjadi pada masyarakat sehingga mengganggu aktifitas sehari-hari. Penyakit mata terjadi karena beberapa faktor, diantaranya keturunan, kelalaian dalam merawat mata, dan usia. Beberapa penyakit mata yaitu katarak, mata juling, rabun dekat (hipermetropia), dan rabun jauh (miopia).

Rabun Jauh (miopia) merupakan suatu kondisi dimana seseorang dapat melihat objek pada jarak dekat dengan baik tetapi mengalami gangguan ketika melihat objek yang jauh. Miopia terjadi karena kesalahan refraksi dengan berkas sinar memasuki mata yang sejajar dengan sumbu optik dibawa ke fokus di depan retina sebagai akibat bola mata yang terlalu panjang dari depan kebelakang atau peningkatan kekuatan daya refraksi media mata. Miopia disebut juga nearsighted, karena titik dekatnya kurang jauh dibandingkan pada emetropia atau mata normal (Saudees, 2013).

Pendeteksian citra mata berbasis pengolahan citra diantaranya ialah deteksi penyakit katarak berbasis perbandingan piksel citra biner dengan menggunakan android (Pramesthi dkk., 2013) dan deteksi rasa kantuk pada pengendara kendaraan bermotor berbasis pengolahan citra digital menggunakan metode Bwarea (Poli dkk., 2013). Perancangan algoritma pengolahan citra mata menjadi citra polar iris sebagai bentuk antara sistem biometrik (Fahmi, 2007).

Bwarea membantu visualisasi hasil dengan menghasilkan gambar yang memiliki nilai wilayah. Dengan metode bwarea ini, dapat diketahui nilai wilayah yang terkandung dalam suatu gambar, sehingga bisa ditentukan dengan sendirinya batas nilai area yang kosong (Tolah dkk., 2015). Berdasarkan hal tersebut, penulis akan mendeteksi rabun jauh (miopia) menggunakan metode Bwarea.

\subsection{Rumusan Masalah}

Rumusan masalah dalam penelitian ini adalah bagaimana performa metode Bwarea dalam mendeteksi rabun jauh (miopia).

\subsection{Tujuan}

Adapun tujuan dari penelitian ini adalah untuk mengetahui performa metode Bwarea dalam mendeteksi rabun jauh (miopia). 


\subsection{Batasan Masalah}

1. Kamera yang digunakan adalah kamera Nikon $D 3200$ dengan pembesaran $55 \mathrm{~mm}$, ukuran image 6.0 MP (3008x2000) dan kualitas image JPEG FINE.

serta kecepatan rana $1 / 60 \mathrm{~s}$.

2. Sampel yang digunakan untuk referensi adalah mahasiswa Jurusan Matematika FMIPA UNTAD tahun 2009 - 2016 yang rabun jauh sebanyak 30 data dan tidak rabun jauh sebanyak 30 data.

3. Sampel yang diuji sebanyak 25 data.

4. Pengambilan gambar dilakukan di ruangan dengan cahaya redup dengan pintu dan jendela tertutup serta pada mata diberikan cahaya dengan intensitas cahaya normal sebesar $800-900$ Lux.

5. Citra yang diolah adalah bagian pupil mata.

\section{METODE PENELITIAN}

Penelitian dilakukan sesuai prosedur di bawah ini :

1. Memulai penelitian.

2. Mengkaji literatur.

3. Mengambil data sampel citra mata mahasiswa Matetamtika FMIPA UNTAD tahun 2009-2016 melalui pengambilan gambar melalui kamera dengan rabun jauh sebanyak 30 data dan tidak rabun jauh sebanyak 30 data.

4. Melakukan pemotongan gambar pada bagian pupil mata.

5. Melakukan pengolahan citra untuk memperoleh nilai Bwarea dari data sampel citra pupil mata.

6. Pengujian normalitas data sampel nilai Bwarea mata rabun jauh dan tidak rabun jauh menggunakan Kolmogorov Smirnov.

7. Menentukan nilai Bwarea mata rabun jauh dan tidak melalui program yang telah dibuat untuk dijadikan referensi dalam analisis data citra pupil mata.

8. Melakukan deteksi data citra pupil mata dengan metode Bwarea sebanyak 25 data.

9. Uji akurasi program metode Bwarea.

10. Selesai.

\section{HASIL DAN PEMBAHASAN}

\subsection{Pengambilan Citra Mata}

Citra mata diambil menggunakan kamera Nikon D3200. Data keseluruhan citra mata yang diperoleh dari pengambilan menggunakan kamera sebanyak 30 data untuk mata rabun jauh dan 30 data untuk mata tidak rabun jauh yang nantinya akan dijadikan referensi dalam penentuan nilai Bwarea mata rabun jauh dan tidak, serta 25 data yang akan diuji pada penelitian ini. 


\subsection{Pemotongan Citra (Croping Citra)}

Setelah pengambilan gambar oleh kamera, langkah pertama yang dilakukan ialah dengan melakukan pemotongan citra (Croping Citra) mata menggunakan program Matlab 2008b.

\subsection{Pencarian Nilai Bwarea Data Citra Pupil Mata}

Proses pencarian nilai Bwarea mata rabun jauh dan tidak rabun jauh dilakukan dengan mengonversi citra pupil mata rabun jauh (ukuran pupil $>4 \mathrm{~mm}$ ) dan citra pupil mata tidak rabun jauh (ukuran pupil $<3 \mathrm{~mm}$ ) ke bentuk numerik berupa nilai Bwarea dengan program yang menggunakan bahasa pemrograman GUI Matlab 2008b. Penggunaan bahasa pemrograman GUI Matlab 2008b bertujuan agar dapat menampilkan citra dengan hasil analisisnya hanya dengan satu tam pilan saja. Proses pencarian nilai Bwarea data citra pupil mata seperti berikut :

1. Memasukkan nama citra pada Matlab agar dapat dibaca program.

2. Melakukan proses grayscale yaitu mengubah citra dari citra berwarna menjadi citra grayscale.

3. Melakukan pemerataan histogram dengan histogram equalization.

4. Melakukan ekstraksi pada citra hasil histogram equalization.

5. Melakukan proses threshold pada citra hasil histogram equalization.

6. Melakukan proses Bwarea untuk memperoleh nilai Bwarea dari citra hasil threshold. Nilai Bwarea akan diperoleh dengan menekan pussbuttuon "nilai Bwarea" pada program yang telah dibuat seperti pada gambar berikut.

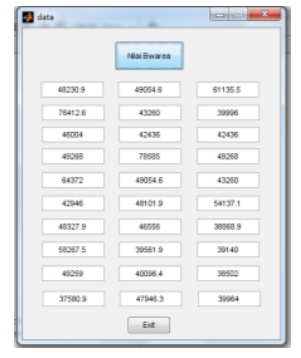

Gambar 1 : Program untuk mencari nilai Bwarea

Pada pencarian nilai Bwarea, data yang digunakan sebanyak 30 baik untuk citra pupil mata rabun jauh maupun untuk citra pupil mata tidak rabun yang nantinya akan digunakan sebagai referensi dalam penentuan nilai Bwareanya. Setelah data nilai Bwarea diperoleh, selanjutnya akan dilakukan uji distribusi normal menggunakan kolmogorov-smirnov dan hasil yang diperoleh menunjukkan data berdistribusi normal dengan konfidensi $\square \alpha=0,05$. Oleh karena itu, data yang digunakan dapat mewakili populasi baik dari mata rabun jauh maupun tidak rabun jauh. 


\subsection{Penentuan Nilai Bwarea}

Penentuan nilai Bwarea dilakukan dengan melihat nilai-nilai Bwarea yang diperoleh. Oleh karena itu, konstanta nilai Bwarea mata rabun jauh $\geq 37580,9$ yang diambil dari nilai terendah, sedangkan konstanta nilai Bwarea mata tidak rabun jauh ialah [0,31659] yang diambil dari nilai tertinggi. Kedua nilai Bwarea tersebut memiliki interval (31659, 37580.9) sehingga data yang nilainya masuk dalam interval ini tidak akan terdeteksi sebagai mata rabun jauh ataupun tidak rabun jauh.

\subsection{Deteksi Citra Menggunakan Metode Bwarea}

Deteksi citra dilakukan dengan menggunakan program identifikasi mata rabun jauh dan tidak rabun jauh. Prosesnya dimulai dengan menekan puss button dengan nama "masukkan citra" dan pilih citra pupil yang akan diidentifikasi. Setelah menekan masukkan citra kemudian tekan proses sehingga akan tam pil nilai Bwarea dari citra. Hasil klasifikasi dari program tersebut, seperti pada gambar berikut.

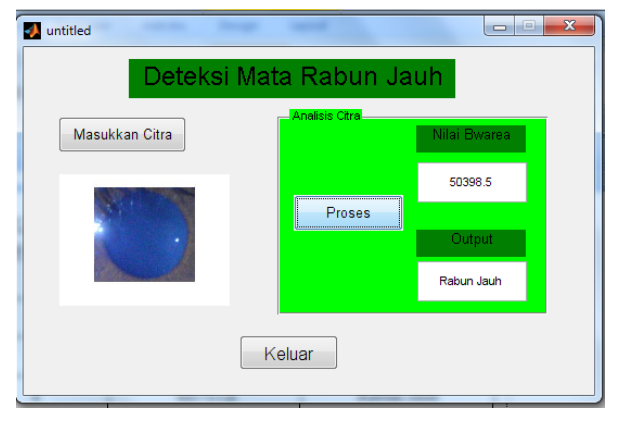

Gambar 2 : Proses Deteksi citra

Pada penelitian ini data yang diuji sebanyak 25 data yang terdiri dari 10 data rabun jauh dan 15 data tidak rabun jauh. Hasil yang diperoleh adalah 10 data terdeteksi rabun jauh, 12 data terdeteksi tidak rabun jauh dan 3 data yang tidak terdeteksi. Akurasi program metode Bwarea sebesar $\frac{22}{25} \times 100 \%=88 \%$.

\section{KESIMPULAN}

1. Konstanta Bwarea mata mahasiswa Matematika FMIPA UNTAD tahun 2009-2016 sebagai berikut.

1. Mata rabun jauh dengan nilai Bwarea $\geq 37580,9$ yang diambil dari nilai terendah.

2. Mata tidak rabun jauh dengan interval nilai Bwarea $[0,31659]$ yang diambil dari nilai tertinggi.

3. Tidak terdeteksi dengan interval nilai Bwarea (31659, 37580.9). 
2. Uji sampel mata mahasiswa Matematika FMIPA UNTAD tahun 2009-2016 baik rabun jauh maupun tidak rabun jauh menggunakan kolmogorov-smirnov adalah berdistribusi normal sehingga sampel dapat mewakili populasi.

\section{DAFTAR PUSTAKA}

[1]. Fahmi, Perancangan algoritma pengolahan citra mata menjadi citra polar iris sebagai bentuk antara sistem biometrik, Karya IImiah, Fakultas Teknik, Universitas Sumatera Utara, 2007, Medan.

[2]. Poli, E.P., Lumenta, A.S.M., Sugiarso, B.A., Wuwung, J.O., Deteksi rasa kantuk pada pengendara kendaraan bermotor berbasis pengolahan citra digital, Jurnal Teknik Elektro dan Komputer, 2(2), 2013, Manado.

[3]. Pramesthi, S., Rizal, A., Atmaja, R.D., Deteksi Penyakit Katarak Berbasis Perbandingan Piksel Citra Biner Dengan Menggunakan Android, Skripsi, Teknik Telekomunikasi, Fakultas Teknik Elektro, Universitas Telkom, 2013, Bandung.

[4]. Rochmad, Moch., Deteksi semangat hidup seseorang melalui pengenalan pola iris mata berbasis artificial neural network, Jurnal Teknik Elektronika, 1(4), 2009, Surabaya, 2328.

[5]. Tolah, R.E.P., Sengkey, R., Rindengan,Y.D.Y., Perancangan Simulasi Otomatis Traffic light Menggunakan Citra Digital Studi Kasus Persimpangan Toar-Lumimuut, Jurnal Teknik Elektro Dan Komputer, 4(4), 2015, Manado, 38-41.

[6]. Saudees, W.b., Kamus Kedektoran Dorland (edisi 29), EGC, 2002, Jakarta. 